\title{
TECNOLOGIA E DEFICIÊNCIA INTELECTUAL: PRÁTICAS PEDAGÓGICAS PARA INCLUSÃO DIGITAL
}

\author{
TECNOLOGIA Y DEFICIENCIA INTELECTUAL: PRÁCTICAS \\ PEDAGÓGICAS PARA INCLUSIÓN DIGITAL
}

\section{TECHNOLOGY AND INTELLECTUAL DISABILITY: PEDAGOGICAL PRACTICES FOR DIGITAL INCLUSION}

\author{
Relma Urel Carbone CARNEIRO ${ }^{1}$ \\ Maria Carolina Branco COSTA ${ }^{2}$
}

RESUMO: O atendimento educacional a estudantes com deficiência intelectual é um tema recorrente nas discussões da área, no sentido de superação de uma visão excludente, que considera a deficiência e ignora as capacidades, buscando $o$ oferecimento de condições reais de acesso ao conhecimento a partir das especificidades. $\mathrm{O}$ uso da tecnologia tem sido apontado como um recurso pedagógico que pode contribuir neste processo, colocando o estudante como protagonista, possibilitando o desenvolvimento de várias áreas do conhecimento. Assim, desenvolvemos um estudo a partir de um projeto de extensão vinculado ao Núcleo de Ensino da Unesp, com o objetivo de propor e avaliar ações pedagógicas através do uso da informática a alunos com deficiência intelectual. O estudo foi realizado em um Centro de Educação Especial com um grupo de dezoito estudantes, de faixa etária compreendida entre 9 e 60 anos. Baseou-se no referencial teórico da pedagogia histórico-crítica e da psicologia histórico cultural, utilizou-se da abordagem qualitativa e teve como procedimento metodológico a pesquisa-ação. Os resultados obtidos a partir das avaliações, relatos das professoras regulares e acompanhamento processual do desempenho dos participantes demonstram que os estudantes envolvidos foram inseridos em ambientes informacionais digitais e o computador atuou como ferramenta pedagógica efetiva no processo de ensinoaprendizagem.

PALABRAS-CHAVE: Educação especial. Deficiência intelectual. Tecnologia. Inclusão digital.

RESUMEN: El atendimiento educativo a estudiantes con deficiencia intelectual es un tema recurrente en las discusiones del área, en el sentido de superación de una visión excluyente, que considera la deficiencia e ignora las capacidades, buscando el ofrecimiento de condiciones reales de acceso al conocimiento a partir de las especificidades. El uso de la tecnología ha sido apuntado como un recurso pedagógico que puede contribuir en este proceso, estableciendo el estudiante como protagonista,

${ }^{1}$ Universidade Estadual Paulista (Unesp), Faculdade de Ciências e Letras, Araraquara - SP - Brasil. Docente do Departamento de Psicologia da Educação e do Programa de Pós-Graduação em Educação Escolar. E-mail: relmaurel@fclar.unesp.br

${ }^{2}$ Universidade Estadual Paulista (Unesp), Faculdade de Ciências e Letras, Araraquara - SP - Brasil. Pedagoga cursando Aprimoramento na USP de Ribeirão Preto. E-mail: ma.carolinabc@gmail.com 
posibilitando el desarrollo de varias áreas del conocimiento. De esa forma, desarrollamos un estudio a partir de un proyecto de extensión vinculado al Núcleo de Enseñanza de la Unesp, con el objetivo de proponer y evaluar acciones pedagógicas a través del uso da informática a los alumnos con deficiencia intelectual. El estudio fue realizado en un Centro de Educación Especial con un grupo de dieciocho estudiantes, de grupo de edad entre 9 y 60 años. Se basó en el referencial teórico de la pedagogía histórico-crítica y psicología histórico cultural, utilizando del abordaje cualitativa y tuvo como procedimiento metodológico la pesquisa-acción. Los resultados alcanzados a partir de las evaluaciones, relatos de las profesoras de enseñanza común y acompañamiento de proceso del desempeño de los participantes demuestran que los estudiantes involucrados fueron inseridos a los ambientes informacionales digitales y la computadora actuó como herramienta pedagógica efectiva en el proceso de enseñanzaaprendizaje.

PALABRAS-CLAVE: Educación Especial. Deficiencia intelectual. Tecnología. Inclusión Digital.

ABSTRACT: The educational service for students with intellectual disability is a recurrent theme in the discussions of this field, in the sense of overcoming an excluding vision that considers the disability and ignores the capabilities, and searching to offer real conditions of access to knowledge coming from specificities. The use of technology has been pointed out as a pedagogical resource that can contribute in this process, making the student the protagonist, allowing the development of a number of areas of knowledge. Thus we have developed a study from an extension project linked to Unesp Teaching Center (Núcleo de Ensino da Unesp), aiming to propose and evaluate pedagogical actions through the use of computing for students with intellectual disability. The study was performed at a Special Education Center with a group of 18 students with ages between 9 and 60 years. It was based on the theoretical references of historical-critical pedagogy and historical-cultural psychology. It also used a qualitative approach and had research-action as its methodological procedure. The results obtained from evaluations, regular teachers' reports and procedural follow-up of the participants demonstrated that the students involved were placed in digital information environments and the computer has acted as an effective pedagogical tool in the process of teaching and learning.

KEYWORDS: Special education. Intellectual disability. Technology. Digital inclusion.

\section{Introdução}

As áreas temáticas envolvidas na apresentação deste artigo suscitam inúmeras reflexões no campo educacional. Deficiência intelectual, tecnologia e prática pedagógica, são temas que envolvem grande complexidade e estão permeados de inúmeros desafios. Interligá-los em uma perspectiva educativa foi um dos objetivos do estudo que realizamos. 
A deficiência intelectual é uma condição que já recebeu inúmeras designações e representações diferenciadas, de acordo com diferentes paradigmas envolvendo as deficiências de modo geral. Até bem pouco tempo, mais precisamente as duas últimas décadas do século passado, pessoas com deficiência intelectual viviam segregadas em ambientes protegidos com pouco ou quase nenhum investimento educacional, consideradas ineducáveis, dentro de uma concepção biologizante, que considerava o déficit e desconsiderava as capacidades. O século XXI se inicia com o fortalecimento de um movimento que contraria a lógica estabelecida, que focava apenas no indivíduo o motivo do desajuste, e pressupõe mudanças bidirecionais, sujeito e sociedade, na busca de melhores condições e oportunidades para todos. Nesta perspectiva, a concepção de deficiência intelectual tem se alterado, deixando de ser vista como totalmente incapacitante, para ser entendida a partir de diferenças individuais e de possibilidades de desenvolvimento de acordo com suas especificidades e oportunidades. Assim, a abordagem teórica, os recursos e estratégias utilizados, bem como as práticas pedagógicas, podem fazer a diferença entre a manutenção de uma visão incapacitante do deficiente intelectual e a percepção do mesmo como sujeito ativo no processo de ensino aprendizagem, capaz de sair de uma posição de não saber para assumir um saber que lhe é próprio. Segundo Fettback e Baldin (2014), “os diferentes contextos históricos, as transformações nas diversas esferas da vida social e os novos comportamentos vêm possibilitando uma nova percepção acerca das pessoas com deficiência".

A tecnologia tem sido cada vez mais incorporada na vida contemporânea, ocupando um lugar de destaque no acesso à informação, que pode ser transformada em conhecimento, nas interações sociais e em funções práticas do cotidiano. De acordo com Bittencourt e Albino (2017), vivemos a emergência de uma sociedade conectada em que o dia a dia da sociedade, das organizações e dos governos depende cada vez mais da tecnologia e principalmente da internet. $\mathrm{O}$ uso da tecnologia como recurso pedagógico pode contribuir no processo de escolarização da pessoa com deficiência intelectual, ao colocar o sujeito aprendiz como protagonista e oferecer um recurso que o coloca na condição ativa de aprendizagem, operando o recurso de maneira participativa e dinâmica, possibilitando o desenvolvimento de várias áreas do conhecimento, como a leitura e escrita, a matemática, as ciências, as artes, entre outras.

Em uma revisão bibliográfica realizada em um importante periódico da área (Revista Brasileira de Educação Especial), envolvendo publicações dos últimos cinco anos, com o objetivo de analisar a produção referente a práticas pedagógicas 
promovidas junto a alunos com deficiência intelectual, verificamos que os recursos pedagógicos utilizados indicam usos de tecnologias mais recentes, como softwares de computadores e vídeo games, mostrando a preocupação e os benefícios das tecnologias para o desenvolvimento de habilidades e conceitos, resultando também na inclusão digital dos estudantes. Conforme os artigos selecionados, os estudos têm sido realizados em diferentes áreas de atuação pedagógica, como, por exemplo, no campo da Alfabetização, Matemática e Educação Física, assim como em diferentes níveis educacionais, desde a Educação Infantil, Ensino Fundamental e EJA. Identificou-se o trabalho pedagógico e de pesquisa de profissionais de diferentes áreas, não apenas do campo da educação, indicando que vários especialistas estão preocupados com o tema, e que existe uma crescente inserção das tecnologias aliadas à prática pedagógica.

Conforme Cunha e Bizelli (2016), trazendo a discussão sobre tecnologia para o cenário da educação, podemos afirmar que o aperfeiçoamento das tecnologias da informação e da comunicação conduz a um novo paradigma educacional, modificando os papeis dos atores escolares. Para Oliveira e Moreira (2015), "as tecnologias podem melhorar e inovar o processo de ensino-aprendizagem, trazendo novas possibilidades, recursos dinâmicos e interessantes, que despertem a atenção, a curiosidade e o interesse pelo conhecimento".

A prática pedagógica é um dos elementos de maior entrave na ação escolar, pois está diretamente relacionada ao oferecimento de condições efetivas capazes de promover o acesso ao conhecimento, uma vez que é a partir do ato pedagógico que o processo de ensino-aprendizagem se efetiva. Para o estudante com deficiência intelectual, mais do que a matrícula e a socialização, o que está em jogo é a apropriação desse conhecimento, dentro de suas possibilidades. De acordo com Fernandes,

Dependendo da qualidade das experiências na vida social, a superação do déficit é um processo que deve ser pensado para qualquer sujeito. A superação do déficit concretiza-se em experiências de formação que visem as funções psíquicas superiores. O trabalho educativo precisa ser orientado para o domínio de atividades culturalmente relevantes, para a elevação dos níveis de generalidade do pensamento e para a capacidade de significar o mundo. Trabalho esse que venha a valorizar mais as possiblidades que as dificuldades em si. (FERNANDES, 2013, p. 229)

Ainda nesta perspectiva de análise, Carneiro e Silva ressaltam que: 
Para além das matriculas é fundamental pensar em estratégias que efetivem a permanência e participação dos alunos com deficiência nas atividades escolares, dado que apesar de ter muitas recomendações nos documentos legais referentes a Educação Especial/Inclusão Escolar, o professor na prática se vê cercado de incertezas, o que muitas vezes o impede de adotar uma didática diferenciada com vistas a empoderar o aluno com deficiência no seu aprendizado acadêmico. (2016, p. 938)

Considerando essas importantes reflexões, desenvolvemos um estudo que buscou investigar a relação de ações pedagógicas permeadas pelo uso da tecnologia e o processo de desenvolvimento e aprendizagem significativa de estudantes com deficiência intelectual.

\section{Método}

Este estudo foi desenvolvido a partir de uma abordagem qualitativa de pesquisa com características do procedimento metodológico designado de pesquisa-ação.

A abordagem qualitativa pode ser definida como, segundo Engel e Silveira (2009), uma abordagem que "não se preocupa com representatividade numérica, mas, sim, com o aprofundamento da compreensão de um grupo social, de uma organização, etc". A pesquisa qualitativa se atém a aspectos da realidade que não podem ser quantificados, e almeja compreender e explicar o exercício dialético das relações sociais.

De acordo com Lüdke e André (1986), a modalidade de investigação nomeada pesquisa qualitativa apresenta como característica central a proximidade entre pesquisador e objeto de pesquisa, entendendo o pesquisador como parte deste universo a ser explorado por meio da investigação. Existe então um envolvimento do pesquisador com o campo e os sujeitos envolvidos.

Faz-se também importante clarificar as bases da pesquisa-ação, que não é considerada uma metodologia:

A luz do que precede, a pesquisa-ação não é considerada como metodologia. Trata-se de um método, ou de uma estratégia de pesquisa agregando vários métodos ou técnicas de pesquisa social, com os quais se estabelece uma estrutura coletiva, participativa e ativa ao nível da captação de informação. (THIOLLENT, 2011, p. 32). 
Segundo Severino (2007), este procedimento é aquele que visa para além da compreensão do fenômeno observado, a intervenção na situação, com vistas a modificála. "A pesquisa-ação propõe ao conjunto de sujeitos envolvidos mudanças que levem a um aprimoramento das práticas analisadas” (SEVERINO, 2007, p. 120).

Em termos gerais:

Como estratégia de pesquisa, a pesquisa-ação pode ser vista como modo de conceber e de organizar uma pesquisa social de finalidade prática e que esteja de acordo com as exigências próprias da ação e da participação dos atores da situação observada. (THIOLLENT, 2011, p. 32).

A pesquisa foi desenvolvida em um Centro de Educação Especial que atende crianças, jovens e adultos a partir de 6 anos de idade, com deficiência intelectual, deficiências múltiplas, Transtornos Globais do Desenvolvimento (TGD) e transtornos de aprendizagem, nos mais diversos graus. O Centro está localizado em uma cidade de porte médio do interior do estado de São Paulo, e recebe alunos de todos os bairros da cidade e de diferentes classes sociais. Os estudantes são atendidos na área pedagógica por pedagogos e psicopedagogos e contam também com atendimentos especializados realizados por profissionais da área da saúde, como fisioterapeutas, fonoaudiólogos, terapeutas ocupacionais e psicólogos. O espaço físico é devidamente estruturado para atender qualitativamente todas as demandas. Em relação ao atendimento educacional, eles são atendidos em três modalidades de cursos, segundo o Plano de Gestão do Centro de Educação Especial: 1) Educação Especial para Alunos com Necessidades Educacionais Especiais; 2) Educação Infantil para Alunos com Necessidades Educacionais Especiais; 3) Ensino Fundamental $\left(1^{\circ}\right.$ ao $5^{\circ}$ anos $)$ para Alunos com Necessidades Educacionais Especiais.

Iniciamos o estudo a partir da exploração do campo de pesquisa, objetivando um conhecimento inicial sobre os sujeitos envolvidos e suas expectativas. Realizamos uma pesquisa documental em anamneses já realizadas pelos profissionais da escola, para conhecimento das características individuais de cada um dos alunos participantes e, em relatórios e planejamentos de aula desenvolvidos anteriormente. Através da observação da rotina das atividades pedagógicas desenvolvidas na sala de aula foi possível estabelecer um primeiro contato com os alunos e suas respectivas professoras. Analisamos também os documentos internos da escola e fizemos uma entrevista com a 
diretora e as professoras, separadamente, com o sentido de compor as informações gerais para o início do trabalho.

Os dados coletados na etapa inicial descrita possibilitaram a organização de um plano de ação mais próximo da realidade e necessidade dos estudantes, condizente com os objetivos inicialmente propostos.

As ações propostas nesta pesquisa se desenvolveram na sala de informática do Centro, que estava desativada por falta de recursos humanos, e foram voltadas aos educandos dos níveis de "Alfabetização" e "Educação para o trabalho", totalizando dezoito alunos. Esta decisão partiu da direção escolar, fundamentada nos critérios de comportamento dos estudantes para utilização dos recursos materiais, envolvimento dos estudantes nas atividades propostas, divisão de horários de outros atendimentos especializados e possibilidades de organização de atividades de maior abrangência pedagógica. Importa ressaltar que a seleção dos níveis para participar das atividades da sala de informática inseridas na pesquisa em questão, foi pensada como uma primeira experiência, dadas as condições organizacionais e estruturais da pesquisa, tendo sido aplicada uma vez por semana, no período matutino, com duração de quatro horas. A intenção da equipe gestora e dos pesquisadores envolvidos é que este espaço possa ser mais ocupado, oferecendo atividades para todos os níveis, de acordo com as características de cada um.

Os participantes foram divididos em quatro turmas de quatro e uma dupla, considerando características e necessidades individuais, e as atividades tinham duração de quarenta minutos para cada turma. Em virtude da especificidade de cada aluno, a maioria das atividades foi planejada individualmente. Algumas atividades comuns foram desenvolvidas com todo o grupo igualmente, tais como o estabelecimento das regras da sala de informática e iniciação aos recursos básicos do computador (trabalho com o uso do mouse, do teclado, aprender a ligar e desligar o computador, entre outros).

Para o planejamento das aulas e atividades foram elaborados quadros esquemáticos individuais, visando facilitar a visualização do conteúdo de ensino de forma objetiva para cada estudante, bem como observações sobre o desenvolvimento das atividades propostas. O quadro continha o nome do estudante, seu nível de desenvolvimento, o nome de sua professora, os objetivos, os conteúdos, os materiais necessários, a descrição das atividades, espaço para anotação do desenvolvimento da atividade, observações e avaliação. 
Os recursos físicos de informática utilizados foram computadores, mouses e headphones. Para a realização das ações, foram utilizados, efetivamente, softwares e jogos virtuais pedagógicos, online e gravados em CD.

\section{Resultados e discussão}

As atividades desenvolvidas durante os oito meses do estudo foram planejadas buscando envolver inicialmente inclusão e acessibilidade digital, atrelado ao conteúdo pedagógico trabalhado em sala de aula, bem como o treino de habilidades espaciais, viso-motoras e funcionais. Para cada aula, foi pensado um tema de trabalho em comum para todas as turmas, de forma que reunisse os eixos descritos acima, almejando atender às necessidades pedagógicas previamente verificadas. Apesar de versarem sobre a mesma temática, as atividades eram voltadas para o atendimento das necessidades de aprendizagem de cada estudante.

O tema de cada aula era introduzido verbalmente de forma dialogada, considerando e aproveitando os conhecimentos prévios da turma. A partir de vídeos, textos, imagens e afins concernentes àquele conteúdo, o contexto histórico e social daquela temática era explorado, contrapondo e aproximando o conteúdo à realidade concreta dos estudantes, de forma a verem sentido e aplicabilidade no tema aprendido. Durante todo o processo eles eram encorajados a manifestarem o entendimento ou as dúvidas, de forma que a proposta pudesse ser reavaliada constantemente e alterada de acordo com as necessidades. O uso do computador e seus recursos tecnológicos acontecia na forma de sistematização do conteúdo apresentado e da exploração de novos aspectos que pudessem ser associados, através de atividades planejadas visando aliar a isto o treino de habilidades motoras, a partir do uso do mouse e de teclas do teclado do computador, e viso-espaciais, através de jogos virtuais que demandassem estas habilidades.

Os jogos escolhidos eram previamente analisados conforme o conteúdo, confrontados com a temática da aula e com as possibilidades de cada estudante em realizá-la, organizadas em sequência didaticamente adequada para então serem propostas. Os critérios de seleção dos jogos virtuais se deram em função de sua correspondência com o tema, buscando especialmente os que envolvessem os estudantes de forma ativa e demandassem a ação dos mesmos; apresentação de resposta 
imediata, indicada via áudio, cor e/ou imagem, e por apresentar diferentes fases, estimulando o interesse dos estudantes e sua autonomia no jogo.

Nos três meses iniciais da pesquisa, o enfoque foi dado para atividades introdutórias, como forma de adaptação às atividades de informática na rotina dos estudantes e ao uso correto dos dispositivos, sendo possível identificar que alguns estudantes demandavam mais atenção e outros tinham um ritmo de aprendizagem mais rápido e avançavam para temas mais complexos. Em decorrência disto, os grupos foram reorganizados em função das temáticas, debates e características individuais de aprendizagem.

$\mathrm{Na}$ sequência, o foco do trabalho voltou-se para atividades de alfabetização e letramento que possibilitassem discussões sobre fenômenos sociais atuais e como o computador poderia ser utilizado como ferramenta de pesquisa, discussão e instrumento para expansão cultural e de apropriação de conteúdos histórico-culturais, distantes da realidade dos mesmos, aproximando-os das funções sociais que este recurso possibilita. Além disto, foram também inseridas aulas voltadas para a aprendizagem do uso de softwares, como Word e Excel, que possibilitam a ampliação da utilização do computador, propondo atividades em que utilizavam estes mecanismos, como a escrita de um texto, a organização de uma tabela, entre outros; além de reforçar a inserção dos estudantes a ambientes informacionais digitais, de forma que ele pudesse ser instrumentalizado no uso de outros softwares.

Os temas trabalhados foram: a) cores primárias e secundárias, cuja aula contou com vídeos explicativos, onde foi possível visualizar o fenômeno da produção das cores secundárias a partir das cores primárias, jogos virtuais que mostravam o processo de formação das cores, nomeação de cada cor e sua relação com elementos reais; b) formas geométricas (círculo, triângulo, quadrado e retângulo), trabalhados a partir de jogos de liga-pontos, de identificação e de correspondência entre forma e nomenclatura; c) temporalidade, a partir do trabalho com unidades de tempo, dias, meses, anos, estações do ano e interpretação de calendário; d) espaço geográfico e localização espacial, através do reconhecimento das características do bairro, bem como da cidade, do estado e do país.

Para que as atividades se tornassem atrativas aos estudantes, propôs-se que os temas de aula e as ferramentas utilizadas no computador fossem articulados: por exemplo, ao trabalhar com o conteúdo "temporalidade", que englobou conceitos de dias, meses, anos, estações do ano e interpretação de calendário. Após as explicações 
teóricas, atividades de fixação do conteúdo e avaliação da compreensão dos estudantes, foi elaborado um calendário digital, utilizando o Word para montagem de uma tabela. Neste calendário, os estudantes puderam utilizar os conceitos aprendidos, bem como as ferramentas do software Word. Finalmente, foi proposto que, a partir do calendário feito, fossem inseridas as atividades pessoais de cada um, construindo uma espécie de "agenda virtual". Desta forma, a individualidade de cada estudante foi valorizada, fazendo com que a atividade pedagógica se aproximasse da realidade de cada um, atraindo a atenção e atribuindo a função social ao calendário, como forma de orientação temporal.

Foram também inseridos áudio-livros cujo conteúdo versou sobre os temas de aula. Este recurso se faz interessante por apresentar o texto em duas formas distintas: escrita e em áudio, o que é interessante para os alunos em processo de alfabetização, visto que podem utilizar do recurso da leitura ou apenas do som para compreender a história.

As avaliações se fizeram necessárias como forma de verificar o que fora realmente apreendido por cada aluno, verificando eventualmente o que deveria ser retomado, o ritmo de aprendizagem e formas de assimilação de cada indivíduo. As avaliações foram realizadas após cada aula, através de uma ou duas atividades que recuperavam todo o conteúdo trabalhado na aula, podendo contar com o auxílio da professora.

Segundo Junior e Kishimoto (2015), verifica-se que as modalidades de mediação entre a interface virtual e o sujeito que dela utiliza, podem versar sobre a mediação dos signos, instrumentos e sujeitos, entretanto, "nem sempre a mediação resultará na internalização de conceitos, mas isso dependerá da zona de desenvolvimento proximal de cada criança".

Em respeito a este conceito, os temas foram pensados para o grande grupo, porém, para cada estudante foram planejadas atividades diferentes, adaptadas às especificidades de cada um, perpassando por jogos virtuais, uso de softwares e CD. Neste tocante, percebe-se que as atividades foram mediadas por signos, instrumentos e sujeito, na figura do professor, que teve o papel de selecionar os jogos virtuais e atividades, em respeito às especificidades de cada estudante, explicar o conteúdo e orientar no desenvolvimento dos comandos entre o estudante e a interface digital.

Os dados obtidos neste estudo revelam que os recursos de informática, atendendo às individualidades dos estudantes, utilizados de forma intencional e 
sistematizada e através da mediação pedagógica, configuraram-se como instrumentos pedagógicos interessantes para a aprendizagem dos estudantes com deficiência intelectual, uma vez que são capazes de motivá-los à aprendizagem, além de inseri-los no universo da informática e do conhecimento, de forma lúdica e ativa.

Os recursos selecionados, como jogos virtuais pedagógicos e atividades em softwares do computador, auxiliaram na coordenação motora, cognitiva e viso-espacial, atuando igualmente na promoção da autonomia dos estudantes no ambiente virtual e na motivação na realização das atividades pedagógicas propostas, uma vez que os estudantes sentiram-se realizados com as tarefas executadas no computador e pelo fato de estarem inseridos no universo virtual.

Para a avaliação do estudo, foram analisadas as fichas de planejamento de atividades individualizadas, observando o desenvolvimento de cada estudante em comparação a si mesmo; questionários preenchidos pelas professoras regulares das turmas envolvidas e entrevista realizada com a diretora do Centro.

Os dados dos questionários respondidos pelas professoras das salas regulares apresentam informações importantes sobre suas percepções acerca das práticas pedagógicas realizadas na sala de informática, como pode ser visto nos seguintes exemplos:

\footnotetext{
"Não notei nenhum aspecto negativo nas aulas de informática, a maioria dos alunos gostam de ir à aula e fazem bom proveito do que é passado pela professora. Além de ser uma atividade diferente para eles, os alunos adquirem conhecimento" (GS, professora da sala regular).

"Estas aulas de informática são de grande importância, pois vêm ajudar o professor nos conteúdos pedagógicos, sendo uma complementação dos mesmos. Os alunos ficam mais empolgados em relação ao curso". (AB, professora da sala regular).
}

Em entrevista, a diretora também ressaltou a importância do trabalho realizado, acentuando a motivação dos estudantes que foi expressa por sua assiduidade no dia das aulas de informática e comentários sobre as atividades.

\section{Conclusão}


A sociedade do século XXI é uma sociedade informatizada. Esta constatação coloca algumas questões que não podem ser ignoradas pela escola, uma vez que todos os estudantes, em maior ou menor grau, estão constantemente em contato com as tecnologias mais variadas, que permeiam a maioria dos ambientes sociais. Assim, muitas vezes, estes estudantes se deparam com signos que muitas vezes lhes são estranhos conhecidos, uma vez que têm consciência de sua existência, porém, não têm o domínio instrumental para agir adequadamente sobre eles, configurando entraves quanto à sua utilização.

Quanto maior o desenvolvimento tecnológico, maior a necessidade de domínio da lógica e das ferramentas que possibilitam a atuação sobre esses recursos, para domínio da vida cotidiana e/ou do mercado de trabalho. Assim, a exclusão digital se torna hoje um grande mecanismo de exclusão social, uma vez que nega ao indivíduo o acesso e domínio de um produto da cultura, que por definição tem que ser de todos e para todos.

Os recursos da tecnologia podem ser importantes ferramentas pedagógicas no ambiente escolar, se explorados de forma contextualizada e mediada. As tecnologias que a informática dispõe, em termos de softwares e jogos digitais com propostas educativas, não são boas ou ruins em si mesmas, mas seus benefícios e/ou malefícios são produto dos processos que as circundam e do uso que o sujeito faz destes recursos, além da forma como estes foram apresentados e assimilados pelo sujeito.

Os participantes deste estudo, estudantes com deficiência intelectual, que ao longo da história foram alijados do processo educacional, e consequentemente privados do desenvolvimento pleno de suas capacidades, viviam também à margem da informatização já anunciada como tão comum. O uso desse recurso como meio de inclusão e instrumento de apoio a todo o processo educacional era um dos objetivos a serem investigados.

Os resultados indicam que os estudantes envolvidos, dentro de suas especificidades e limitações, se apropriaram dos conteúdos ministrados, além de demonstrarem maior domínio motor dos hardwares do computador, bem como maior domínio operacional dos softwares, ao serem observados em perspectiva processual. Viu-se também que as aulas de informática trouxeram maior motivação para os conteúdos pedagógicos de alfabetização, que foram trabalhados neste ambiente de forma complementar à sala de aula. 
As avaliações, realizadas após as atividades e a partir do relato das professoras responsáveis por cada turma, reiteram as conclusões obtidas no estudo, demonstrando que os estudantes envolvidos foram inseridos em ambientes informacionais digitais, e o computador atuou como efetiva ferramenta pedagógica auxiliar ao processo de ensinoaprendizagem.

Verificou-se que as dificuldades iniciais de grande parte dos estudantes, sobretudo advindos da turma: "Alfabetização", no manuseio de periféricos (como mouse e teclado) do computador foram sanadas já nas primeiras aulas, com auxílio e atividades que exploravam movimentos com o uso destes.

Observou-se, entretanto, que alguns alunos, com deficiência intelectual e/ou motora mais acentuada, ainda apresentavam dificuldades motoras e cognitivas no final do processo (observadas em atividades como manejar adequadamente o mouse, clicar e arrastar, e apresentando também dificuldades de memorização sobre o uso das ferramentas dos softwares), demandando maior atenção e apoio. Reforça-se assim a importância do trabalho e de sua continuidade.

Finalmente, entende-se que a tecnologia deve ser utilizada a serviço da emancipação do sujeito e expandida a todos os setores sociais, atendendo à diversidade de estudantes, em suas mais variadas condições, sociais e intelectuais. A real inserção dos sujeitos em uma sociedade se inicia pelos processos educativos e, neste sentido, defende-se que a educação emancipadora precisa ser mediada e, sobretudo, democratizada, para que esteja a serviço de todos e cumpra seu real significado: de desenvolvimento de todas as potencialidades do ser.

\section{REFERÊNCIAS}

BITTENCOURT, P. A. S.; ALBINO, J. P. O uso das tecnologias digitais na educação do século XXI. Revista Ibero-Americana de Estudos em Educação. Araraquara, v. 12, n. 1, p. 205-214, jan-mar/2017. Disponível em: <http://seer.fclar.unesp.br/iberoamericana>. Acesso em: 20 abr. 2017.

CARNEIRO, R. U. C.; SILVA, S. S. Inclusão escolar de alunos público alvo da educação especial: como se dá o trabalho pedagógico do professor no ensino fundamental I? Revista Ibero-Americana de Estudos em Educação. Araraquara, v. 11, n. esp. 2, p. 935-955, 2016. Disponível em: <http://seer.fclar.unesp.br/iberoamericana>. Acesso em: 20 abr. 2017.

CUNHA, M. D.; BIZELLI, J.L. Caminhos para TIC em sala de aula sob a perspectiva dos professores. Revista on line Política e Gestão Educacional. Araraquara, v.20, n.2, 
p.282-300, abr-jun/2016. Disponível em: 〈http://seer.fclar.unesp.br/rpge/index〉. Acesso em: 19 abr. 2017.

ENGEL, T. G.; SILVEIRA, D. T. (Org.). Métodos de Pesquisa. $1^{\text {a }}$ Ed. Rio Grande do Sul: Editora da UFRGS, 2009.

FERNANDES, A. P. C. S. A escolarização de alunos da EJA em turma especial em tempo de política de educação inclusiva. Revista on line Política e Gestão

Educacional. Araraquara, n. 15, p. 228-234, 2013. Disponível em:

<http://seer.fclar.unesp.br/rpge/index>. Acesso em: 20 abr. 2017.

FETTBACK, C. S.; BALDIN, N. O contexto da educação especial na perspectiva da educação inclusiva: as vozes dos professores e dos familiares na rede municipal de ensino de Joinville (SC). Revista on line Política e Gestão Educacional. Araraquara, n.17, p.167-186, 2014. Disponível em: 〈http://seer.fclar.unesp.br/rpge/index>. Acesso em: 19 abr. 2017.

JUNIOR, W. A.; KISHIMOTO, T. M. Jogos digitais, mediação e a psicologia históricocultural. In: IX Amostra de Pesquisas em Educação. Anais da IX Amostra de Pesquisas em Educação. Araraquara: UNESP, 2015.

LÜDKE, M.; ANDRÉ, M. E. D. A. Pesquisa em educação: abordagens qualitativas. São Paulo: EPU, 1986.

OLIVEIRA, V. A.; MOREIRA, H. As tecnologias da informação e comunicação como mediação pedagógica no curso de pedagogia. Revista Ibero-Americana de Estudos em Educação. Araraquara, v. 10, n. 2, p. 371-389, 2015. Disponível em: <http://seer.fclar.unesp.br/iberoamericana>. Acesso em: 20 abr. 2017.

SEVERINO, A. J. Metodologia do trabalho científico. 23 ed. São Paulo: Cortez, 2007. THIOLLENT, M. Metodologia da pesquisa-ação. 18 ed. São Paulo: Cortez, 2011.

\section{Como referenciar este artigo}

CARNEIRO, Relma Urel Carbone.; COSTA, Maria Carolina Branco. Tecnologia e deficiência intelectual: práticas pedagógicas para inclusão digital. Revista on line de Política e Gestão Educacional, Araraquara, v.21, n. esp. 1, p. 706-719, out./2017. Disponível em: <http://dx.doi.org/10.22633/rpge.v21.n.esp1.out.2017.10449>. ISSN: 1519-9029.

Submetido em: 28/04/2017

Aprovado em: 10/09/2017 